\title{
Radiofrequency thermal ablation in the treatment of malignant tumors
}

\author{
An Essay \\ submitted for partial fulfillment of master degree \\ in general surgery
}

By

Hussein Abd Elrazek Hussein

M.B., B.CH

\begin{abstract}
Under Supervision of
Professor Dr. Khalid Zaky Mansour

Professor of General Surgery

Faculty of Medicine - Ain Shams University

Professor Dr. Saleh Abd EI Kader Ahmed

Professor of General Surgery

Faculty of Medicine - Ain Shams University

Dr. Ahmed Mohammed Nafei

Lecturer of General Surgery

Faculty of Medicine - Ain Shams University
\end{abstract}

Faculty of Medicine

Ain Shams University

2008 


\begin{abstract}
Radiofrequency ablation (RFA) provides an effective technique for minimally invasive tissue destruction. An alternating current delivered via a needle electrode causes localized ionic agitation and frictional heating of the tissue around the needle. Image-guided, percutaneous ablation techniques have been developed in most parts of the body, but the most widely accepted applications are for the treatment of hepatocellular carcinoma (HCC) in early cirrhosis, inoperable colorectal liver metastases, inoperable renal cell carcinoma and inoperable primary or secondary lung tumors. The procedures are well tolerated and the complication rates low. Most treatments in the lung, kidney and for HCC are performed under conscious sedation with an overnight hospital stay or as a day-case. Limitations of RFA include the volume of tissue that can be ablated and most centers will treat 3-5 tumors up to 4-5 cm in diameter. Early series reporting technical success and complications are available for lung and renal ablation. Liver ablation is better established and 5-year survival figures are available from several centers. In patients with limited but inoperable colorectal metastases, the 5-year survival ranges from 26 to $30 \%$ and for HCC it is just under 50\%. In summary, RFA provides the opportunity for localized tissue destruction of limited volumes of tumor; it can be offered to nonsurgical candidates and used in conjunction with systemic therapy.
\end{abstract}

\section{Introduction:}

Heat has been used in medicine as long as history. Ancient Egyptian medicine used heated metal bars and the Greeks used heated stones to stop bleeding. Electrocautery has been used for decades in surgery to fulgurate, cauterize, cut tissue, and to stop bleeding. The first experiment in radiofrequency ablation (RFA) of living tissues is credited to d'Arsonval, who demonstrated that an alternating electric current greater than $10 \mathrm{kHz}$ could pass through living tissue without causing neuromuscular excitation. ${ }^{1}$

The radiofrequency (RF) thermal ablation works by converting RF waves into heat. A high frequency alternating current (100 to $500 \mathrm{kHz}$ ), mostly $460 \mathrm{kHz}$, passes from an uninsulated electrode tip into the surrounding tissues and cause ionic vibration as the ions attempt to follow the change in direction of the rapidly alternating current. This ionic vibration causes frictional heating of the tissues surrounding the electrode, rather than the heat being generated by probe itself. The goal of radiofrequency ablation (RFA) is to achieve local temperatures such that tissue destruction occurs. ${ }^{2}$ The RF probe itself does not release heat and local tissue heating depends on the thermal conductivity of the tissue and distance from the probe. Dependent on time and tissue perfusion, coagulative necrosis occurs when the tissue is heated to a temperature greater than $60^{\circ} \mathrm{C} .^{3}$

\section{The radiofrequency device:}

There are four RFA systems currently available. They differ in the power of the generator, the technique used to maximize treatment volumes, the size of the needles, and in the electrical parameters monitored to maximize energy deposition. ${ }^{4}$ Two of the four systems (RITA Medical Systems, Inc. Mountain View, CA, and Radio-Therapeutics Corp. Mountain View, CA) use coaxiallydeployed hooks or inner tines which expand into the tumor after the outer needle are placed into the tumor. ${ }^{5}$ The third is Radionics System and requires a pump that perfuse chilled saline through the hollow ports inside the needles, Needle gauges are $17.5 \mathrm{G} .{ }^{1}$ The $4^{\text {th }}$, is Berchtold system: infuses normal saline to increase the burn, Berchtold system is the only vendor with FDA with MR-compatible probes. ${ }^{6}$

\section{Guidance Techniques and Applications:}

RFA is generally done in a room devoted to $\mathrm{CT}$ or ultrasound imaging. Each RFA treatment takes about 12 to 30 minutes and the total procedure will be completed in one to three hours depending on how many tumor sites have to be treated. ${ }^{7}$ The RF needle electrode is advanced into the tumor to be treated via a percutaneous, laparoscopic, or open route. Accurate imaging is essential for successful in situ tumor ablation (Tumors that are not seen cannot be targeted). And the choice 
of RFA approach should be individualized according to size, location of the tumor and patient's condition. ${ }^{8}$

\section{Radiofrequency in the liver tumors:}

Hepatocellular Carcinoma (HCC) is one of the most common solid tumors in the world and its incidence has sharply increased within last 2 decades. This rise has been attributed to the concomitant increase in patients infected with hepatitis $\mathrm{C}$ virus and hepatitis B virus. ${ }^{9}$ The liver has a rich systemic and portal blood supply, providing a potentially abundant source of circulating neoplastic cells. ${ }^{10}$ Nodular hepatomas are optimally suited for RFA as they are often encapsulated, soft tumors surrounded by firm cirrhotic parenchyma which increase the efficiency of thermal ablation and reduce risk of recurrence. ${ }^{1}$ Ideal tumors are smaller than $3 \mathrm{~cm}$ in diameter completely surrounded by hepatic parenchyma, $1 \mathrm{~cm}$ or deeper to the liver capsule and $2 \mathrm{~cm}$ or more away from large hepatic or portal veins, The choice of RFA approach should be individualized according to size, location of the tumor and patient's condition. ${ }^{11}$

\section{Radiofrequency in the renal tumors:}

Nephron sparing techniques such as partial nephrectomy have been shown to be as effective as the traditional total nephrectomy, while providing a reduced morbidity and better preservation of renal function. ${ }^{12}$ several groups have explored local ablation techniques in early small renal cell carcinoma and RFA has been very successful. ${ }^{13}$ Contraindications may include a poor life expectancy of $<1$ year, multiple metastases, or difficulty for successful treatment due to size or location of tumor. Large tumors $(>5 \mathrm{~cm})$ or tumors in the hilum or central collecting system are not typically recommended for RF ablation. ${ }^{14}$

\section{Role of radiofrequency in lung cancer:}

Lung tumors are well suited to RF ablation because the surrounding air in adjacent normal parenchyma provides an insulating effect, thus facilitating energy concentration within the tumor tissue, the lung RF ablation can be safely and effectively performed via a percutaneous, transthoracic approach. ${ }^{15}$ Radiofrequency ablation can be equally well applied to small lung tumors, either primary or secondary. After completion of the procedure, a single expiratory scan is obtained throughout the thorax and viewed at a narrow window width to detect subtle pneumothorax. ${ }^{16}$

\section{Recent applications of radiofrequency in surgery:}

Recent applications of radiofrequency in surgery are the following: breast-conserving surgery to ablate the malignant tumor and surrounding margin of tissue, ${ }^{17}$ locally advanced cases of pancreatic tumors, ${ }^{18}$ sacral chordoma $^{19}$ and ablation for palliation of painful skeletal metastases. ${ }^{20}$

\section{Conclusion:}

RFA will likely play a significant role in the future in the treatment of the patients with both primary and metastatic hepatic tumors, renal cell carcinoma and lung cancer who are not surgical candidates. Radiofrequency ablation represents a relatively safe, quick and highly effective treatment and the best results of RFA are expected with tumor size lesion 3$5 \mathrm{~cm}$. Laparoscopic procedure proved to be feasible with low rate of serious complications. 


\section{References:}

1- Abu Hilal M, Breen DJ: Radiofrequency thermal ablation in the treatment of malignant tumors. Recent Advanced in Surgery 2006; 29: 75-93.

2- Lin SM, Lin CJ, Hsu CW, Chen YC: Randomized controlled trial comparing percutaneous radiofrequency thermal ablation, percutaneous ethanol injection, and percutaneous acetic acid injection to treat hepatocellular carcinoma of $3 \mathrm{~cm}$ or less. Gut 2005; 54: 1151-1156.

3- Gazelle Scott, Goldberg SN, Solbiati L, Livraghi T: Tumor ablation radiofrequency energy. Radiology 2000; 217: 633-646.

4- Lencioni R, Dellapina C, Bartolozzi C: Percutaneous image guided radiofrequency ablation in the therapeutic management of hepatocellular carcinoma. Abdominal Imaging 2005; 30: 401-408.

5- Siperstien AE, Gitomirski A: History and technological aspects of radiofrequency thermoablation. Cancer J 2000; 5: 293303.

6- Gannon CJ, Curley SA: The role of focal liver ablation in the treatment of unresectable primary and secondary malignant liver tumors. Semin Radiat Oncol 2005; 15: 265-272.

7- Christopher J, Curley A: The role of focal liver ablation in the treatment of unresectable primary and secondary malignant liver tumors. Semin Radiat Oncol 2005; 15: 265-272.

8- Lewin JS, Connell CF, Duerk JL, et al: Interactive MRI guided radiofrequency interstitial thermal ablation of abdominal tumors: Clinical trail for evaluation of safety and feasibility. J Magn Reson Imaging 1998; 8: 40-47.

9- Elizabeth M, Amr S, Kadry I, Ahmed H, Ibrahim A, Mohamed R, EL-Hamzawy H: Pattern of hepatocellular carcinoma incidence in Egypt from a population-based cancer registry. Hepatology Research 2008; 38: 465-473.

10-Terayama N, Terada T, Nakanuma Y: A morphometric and immunohistochemical study on angiogenesis of human metastatic carcinomas of the liver. Hepatology 1996; 24: 816-819.
11-Goldberg SN, Gazelle GS: Radiofrequency tissue ablation: Physical principles and techniques for increasing coagulation necrosis. Hepato-Gastroenterology 2001; 48: 359-367.

12-Ronald J: Imaging-guided radiofrequency ablation of renal masses. Radio Graphics 2004; 24: 59-71.

13-Gillams AR: The use of radiofrequency in cancer. British Journal of Cancer 2005; 92: 1825-1829.

14-Mayo WW, Dupuy DE, Parikh PM, Pezzullo JA, Cronan JJ: Imaging guided percutaneous radiofrequency ablation of solid renal masses: Techniques and outcomes of 38 treatment sessions in 32 consecutive patients. Am J Roentgenol 2003; 180: 1503-1508.

15-Lencioni R, Crocetti L, Cioni R, Mussi A, Fontanini G, Ambrogi M, Franchini Ch, Cioni D, Fanucchi O, Gemignani R, Baldassarri R, Angeletti CA, Bartolozzi C: Radiofrequency ablation of lung malignancy: where do we stand? Cardovasc Intervent Radial 2004; 27: 581-590.

16-Fernando C, Alberto De H, Rodney J, Sebastian G, William E, Percival O, Neil A, Chandra B, James D: Radiofrequency ablation for the treatment of non small cell lung cancer in marginal surgical candidates. The Journal of Thoracic and Cardiovascular Surgery 2005; 129(3): 639644.

17-Bland KL, Gass J, Klimberg VS: Radiofrequency, cryoablation, and other modalities for breast cancer ablation. Surg Clin North Am 2007; 87(2): 539-550.

18-Spiliotis JD, Datsis AC, Chatzikostas P, Kakelos SP, Christopoulou AN, Rogdakis AG: Pancreatic cancer palliation using radiofrequency ablation. A new technique. Cancer Ther 2005; 3: 379-382.

19-Nassar A, Nohra C, Khoneisser A: Use of radiofrequency ablation for the palliative treatment of sacral chordoma. Am J Neuroradiol 2004; 25: 1589-1591.

20-Halpin RJ, Bendok BB, Sato KT, Liu JC, Patel JD, Rosen ST: Combination treatment of vertebral metastases using image guided percutaneous radiofrequency ablation and vertebroplasty: A case report. Surg Neurol 2004. 